\title{
Pricing of Games as a Service: An Analytical Model for Interactive Digital Services with Hedonic Properties
}

\author{
Tayfun Keskin \\ The University of Texas Rio Grande Valley \\ $\underline{\text { Tayfun.Keskin@utrgv.edu }}$
}

\begin{abstract}
This study explores optimal pricing strategies in games and other interactive digital goods under incomplete information, when bundling is an option. Drawing from research on the pricing of information goods, we propose a pattern of optimal pricing strategies in which hedonic characteristics affect the utility of interactive digital goods and services. This is a new approach to games, to treat them as a service to determine pricing strategies. Findings reveal that there is an optimal pricing solution for firms in the gaming industry. This finding holds both in bundling and non-bundling cases.

Utilizing analytical modeling methodology, we propose pricing-inspired business strategies to the firms operating in the digital gaming industry. Our findings could also be applied to other hedonic interactive digital goods and services. Overall, this study contributes to the existing pricing theories in digital services and information goods.
\end{abstract}

\section{Introduction}

Content release strategy of the gaming industry was almost identical to the physical goods prior to the internet era. For example, once Super Mario is released, all the game content is packed into a fixed package, and the players did not get any new content until Super Mario 2 cartridge is released (see figure 1.) This strategy seems to be constrained by technology of the game production rather than by business motives. Moreover, connecting a digital service to a physical good made it easier to utilize conventional pricing models. Nowadays, game developers can release new content to players whenever they want. Many mobile apps or online games release new updates in a matter of weeks, or even days. Given this flexibility, determining optimized pricing and content release strategies based on business motives has become an important decision.
One of the most important motives for the game developer to release new contents of the game is to balance between getting desirable content delivered and minimizing the annoyance caused to players. It is obvious that game developers have the incentive to deliver desirable content to players. Frequent release of new content provides new excitement to players, and invoke in game purchasing. For the annoyance caused to players, it is not only referring to the hassle caused by frequency update notifications, it also includes the cost incurred when players are trying to get used to the new contents or user interfaces. In addition, frequent additions could complicate the game. It could potentially harm in game social interactions and deter new players [1].

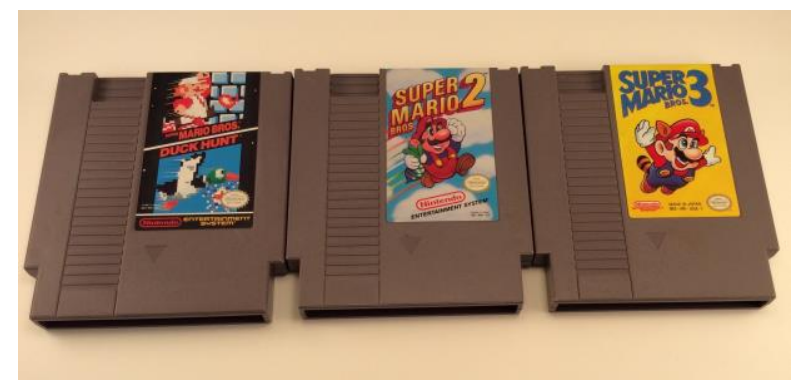

Figure 1: Super Mario Series Cartridges

Our study aims to model this trade-off caused frequent updates to generate revenue. We also investigate how social interactions among gamers could affect the developers' optimal decision. Of course, in practice, this analytical model should be tested with empirical estimates so that we can know more about how exactly the model works for different types of games or different player pools.

The main contribution of this research study is to clarify how several important mechanisms, which are well known to the game developers, work together in an economic model. For example, the game difficulty 
has to be at the correct level because if the game is too difficult, it could deter new players. On the other hand, if it is too easy, competitive players may leave. Also, if the developers release new content too frequently user do not have enough time to get used to them. Yet, without new releases, the developer cannot response to user's preference accordingly. Leveraging the nature of social interaction in the game makes it easier for the players to learn about the new content and gain the most out of it. None of these mechanisms is foreign to the game industry. However, it is because these mechanisms interact and affect each other, putting them together makes the whole system very complicated to analysis without a formal model. By building an economic model with rational agent, we can apply the tools we use in economics to learn about to how the above mechanisms work.

Our analytical model also provides insight to operational decisions (such as when and how much a game developer should release new content.) In addition, if they can release new content to a particular group of players, how they should pick those players. We hope that the model will provide us with a tool to hint the answer to these questions and hint how the decision be affected by the nature of player pool, size of game, nature of game, companies' fame, and the cost of producing new contents.

Understanding the optimal content release frequency is important for the game developers provide good user experience for players. Our preliminary investigation revealed that there is substantial amount of comments in Google Play and Apple App Store declaring the annoyance caused by too frequent updates. In addition, there are even more comments concerning not enough new content when we are looking at the game-associated forums.

Finally, our analytical model hints the direction of how making use of game data to improve bundling decisions. As mentioned before, social interaction plays an important role in determining optimal content release strategy. Therefore, with the proper measure of the degree of social interactions and other characteristics of the game, we can determine the strategy better. Big-data researchers in the gaming industry can also benefit from this model. The insight we get from an economic model can help us to narrow down what we should be looking at in the sea of game data.

In the recent years, online games and software as a service have been popular research topics. However, to our knowledge, this is the first paper investigating pricing strategies games as a service.

\section{Literature Review}

Contemporary games typically utilize cloudcomputing technologies. The gaming industry has been embracing cloud computing because of its reduced operational costs, flexibility, scalability, rapid deployment, remote access and mobility, access to innovation, efficient use of computing resources, and green computing [2]. Cloud computing has three service models: Infrastructure as a Service (IaaS), Platform as a Service (PaaS), and Software as a Service (SaaS). Conventional digital games are moving from away from physical software packages (i.e., Cartridges and disks) to SaaS platforms. The new SaaS based gaming platform is called cloud gaming, or games as a service (GaaS) [3].

SaaS is not only a popular for gaming services, but it also drives the overall growth of the cloud computing industry. In 2016, SaaS applications generated more than half of the cloud computing industry revenue [4].

This study investigates the impact of interactive digital goods pricing strategies on the sales revenues of GaaS products. Therefore, this section discusses the prior studies on price discount-based pricing and bundling strategies.

\subsection{SaaS - GaaS Intersection}

Cloud computing, particularly SaaS, has been a popular research topic in the last decade $[5,6,7,8,9$, 10]. Numerous studies have presented definitions of major concepts, systems structures, stakeholders, and technologies, as well as potential future research topics in the cloud computing area [2, 4, 9]. However, $\mathrm{GaaS}$ is rarely discussed in cloud computing research primarily because it is covered under SaaS and other emerging technology categories. Discussion of these "emerging technology" classifications is essential for information systems research as the managerial aspects of cloud computing enhances capabilities and performance of the information technology (IT) artifact [11].

An alternative key study pillar of cloud computing research is to discuss new gaming technologies that can be offered through SaaS category. The overview of $\mathrm{GaaS}$ is essential to investigate these new technologies and capabilities related to cloud 
computing and provide an overarching picture for the pricing of these emerging technologies $[2,12]$.

Prior research has already addressed perception, adoption, privacy and security issues regarding the SaaS concept $[13,14,15]$, yet we were not able to identify any studies on business models or pricing research on SaaS.

\subsection{Pricing Strategies}

Game pricing strategies include bundling and price discounts. Price discount is so essential, most popular and effective pricing strategy employed to increase sales is freemium. Giving away the initial product free affects the evaluation of gamers on product utility [16, 17]. Contemporary literature has shown a positive impact of the price discount promotion on the gamer's value perception of the product, intention to purchase and purchase behavior, as well as the revenue performance of the seller. Impulse buying also has a predominant effect on sales increase, and it has been investigated in a number of digital goods domains [16, 18].

The ubiquitous property of the GaaS domain has unsurprisingly expanded the gaming market. Mobile games are the highest-earning segment in the SaaS domain when direct and indirect revenues are considered. For example, the steady increase in the number of mobile phone users playing online games have been and easily observable in our classrooms. In addition, ad-hoc surveys we conducted over the years indicates that gamers are getting more and more comfortable for paying for bundled services and freemium digital interactive goods [4].

Recent seminal articles we identified in the pricing of bundling products mainly utilized empirical methods such as Mishra and Mishra [19]. However, there has been earlier studies that used analytical modeling [20]. Despite these relevant studies, anecdotally, we observed that practitioners lack analytical pricing and bundling strategies in the GaaS domain. Perhaps, this is because prior studies on discount-based pricing and bundling strategies focused their impact on the perceived value of products and the buying intention of gamers rather than hedonic properties of games and other digital goods.

\section{Model}

We characterize game markets with a competitive classical two period model with a $j$ number of offerings. Initially, competing firms start with asymmetric market shares, which is more realistic than identical market shares. Next, we use this model to investigate how prices and market shares would change over time and to explain strategies for advanced strategies that include bundling of GaaS offerings. Figure 2, demonstrates the nature of our gaming market.

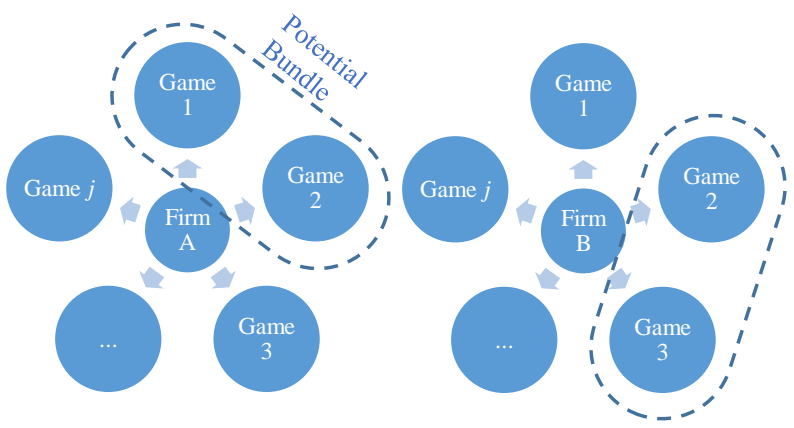

Figure 2: Market Structure in the Game Market Model

Beyond the classical model, we expand the market with GaaS services and time-inconsistent behavior.

The notation used in this paper is in Table 1.

Table 1. Notation

\begin{tabular}{ll}
\hline Term & Definition \\
\hline$u$ & Gamer's utility \\
$i$ & Firm index: $i \in\{\mathrm{a}, \mathrm{b}\}$ \\
$t$ & Period: $t \in\{0,1,2\}$ \\
$c_{s}$ & Cost of switching: $c_{s} \sim \mathrm{U}[0, \theta]$ \\
$j$ & GaaS index for bundling: $j \in\{1,2,3, \ldots\}$ \\
$e$ & Network effect on $u$ \\
$\alpha$ & Marginal shifting cost \\
$p_{t}^{i}$ & Price of firm $i$ in period $t$ \\
$q_{t}^{i}$ & Quantity sold by firm $i$ in period $t$ \\
\hline
\end{tabular}

The gaming market are served by two firms ( $a$ and $b$ ) with asymmetric initial market shares:

$$
0 \leq q_{0}^{b}<0.5<q_{0}^{a} \leq 1
$$

The asymmetric market share assumption benefits the model in two ways. First, it provides a more realistic representation of current GaaS markets. Second, it covers a wider range of theoretical scenarios than an equal-market-share case. 
We also assume that, in the market setting above, there is a continuum of gamers uniformly distributed between firms $a$ and $b$. This horizontal differentiation (which indicates that GaaS characteristics across games are fixed) is due to inherent characteristics of GaaS (such as gamer taste, ease of operation, configurability, compatibility and security perception) rather than the physical location.

\subsection{Basic Model}

We consider a one-shot game theoretical model in which firms commit prices $p_{l}, p_{2}$. Gamers make purchase decisions based on their hedonic utilities. Let $p_{t}^{i}$ represent the price of firm $i$ in period $t$. The term $x^{i}$ is the distance of the gamer from buying firm $i$. The indifferent gamer for firm $a$ in the second period can be characterized as:

$$
u-\alpha x^{a}-p_{2}^{a}=u-\alpha\left(1-x^{a}\right)-p_{2}^{b}-s
$$

This indifferent gamer boundary determines new market shares for firm $a$ and $b$ at the end of the second period. In the cloud computing industry, utility is derived from using per unit of service but in the baseline model, we do not allow for differentiated services.

We use backward induction to find equilibrium prices and quantities sold to represent market shares. Our primary goal is to determine if there is an optimal solution for firm revenues and pricing.

Firm $b$ 's indifferent gamer is:

$$
u-\alpha\left(1-x^{b}\right)-p_{2}^{b}=u-\alpha x^{b}-p_{2}^{a}-s
$$

We can determine the new allocation of the market shares for firm $a$ and $b$ at the end of the second period by finding the quantity of switching gamers. To find second term market shares in terms of second period prices, we start with switching costs:

$$
\begin{aligned}
& s^{a}=\alpha\left(2 x^{a}-1\right)+p_{2}^{a}-p_{2}^{b} \\
& s^{b}=\alpha\left(1-2 x^{b}\right)-p_{2}^{a}+p_{2}^{b}
\end{aligned}
$$

Let $n_{t}^{j k}$ be the quantity of gamers who bought from $k$ in period $t-1$, and firm $j$ in period $t$. For example, gamers who switched to firm $b$ from firm a in period 2 are represented as $n_{2}^{b a}$.

Gamers staying with firm $a$ :

$$
\begin{aligned}
& n_{2}^{a a}=\int_{0}^{q_{1}}\left(\int_{\alpha(2 x-1)+p_{2}^{a}-p_{2}^{b}}^{\theta} \frac{1}{\theta} d s\right) d x \\
& =\frac{q_{1}\left(\alpha\left(1-q_{i 1}\right)-p_{2}^{a}+p_{2}^{b}+\theta\right)}{\theta}
\end{aligned}
$$

Gamers switching from firm $a$ to firm $b$ :

$$
\begin{gathered}
n_{2}^{b a}=q_{1}-n_{2}^{a a} \\
=\frac{q_{1}\left(\alpha\left(q_{i 1}-1\right)+p_{2}^{a}-p_{2}^{b}\right)}{\theta}
\end{gathered}
$$

Gamers staying with firm $b$ :

$$
\begin{aligned}
& n_{2}^{b b}=\int_{q_{1}}^{1}\left(\int_{\alpha(1-2 x)-p_{2}^{a}+p_{2}^{b}}^{\theta} \frac{1}{\theta} d s\right) d x \\
& =\frac{\left(1-q_{1}\right)\left(\alpha q_{1}+p_{2}^{a}-p_{2}^{b}+\theta\right)}{\theta}
\end{aligned}
$$

Gamers switching from firm $b$ to firm $a$ :

$$
\begin{gathered}
n_{2}^{a b}=1-q_{1}-n_{2}^{b b} \\
=\frac{\left(q_{1}-1\right)\left(\alpha q_{1}+p_{2}^{a}-p_{2}^{b}\right)}{\theta}
\end{gathered}
$$

Market share for firm $a$ at the end of period 2:

$$
\begin{aligned}
& q_{2}^{a}=n_{2}^{a a}+n_{2}^{a b} \\
& =q_{1}+\frac{p_{2}^{b}-p_{2}^{a}}{\theta}
\end{aligned}
$$

Market share for firm $b$ at the end of period 2:

$$
\begin{aligned}
& q_{2}^{b}=n_{2}^{b b}+n_{2}^{b a} \\
= & 1-q_{1}+\frac{p_{2}^{a}-p_{2}^{b}}{\theta}
\end{aligned}
$$

Firm $j$ maximizes its second period profit.

$$
\max _{p} \pi_{2}^{j}=p_{2}^{j} q_{2}^{j}
$$

First order conditions give us equilibrium prices as:

$$
p_{2}^{a *}=\frac{\left(1+q_{1}\right) \theta}{3}
$$




$$
=\frac{\left(2-q_{1}\right) \theta}{3}
$$

Equilibrium quantities sold are:

$$
\begin{gathered}
q_{2}^{a *}=\frac{\left(1+q_{1}\right)}{3} \\
=\frac{\left(2-q_{1}\right)}{3}
\end{gathered}
$$

As a result of the profit maximization where gamers may switch, we obtain second period profits as a function of quantities sold in the first period:

$$
\begin{aligned}
& \pi_{2}^{a *}=\frac{\left(1+q_{1}\right)^{2} \theta}{9} \\
& \pi_{2}^{b *}=\frac{\left(2-q_{1}\right)^{2} \theta}{9}
\end{aligned}
$$

Next, we follow the same procedure for period 1 . First, we identify the indifferent gamers to find switching costs $s_{i}$ in terms of $x_{i}^{j}$ and prices. Then we solve the maximization problem for the first period profits to find equilibrium prices and quantities sold.

Total profits can be found as a function of initial quantities sold and switching costs:

$$
\begin{aligned}
\pi_{1}^{a *} & =\frac{\left(13+9 q_{0}\right)\left(5 \theta+7 q_{0} \theta\right)}{529} \\
\pi_{1}^{b *} & =\frac{\left(10-9 q_{0}\right)\left(18 \theta-7 q_{0} \theta\right)}{529}
\end{aligned}
$$

Theorem 1: There exists a solution for the maximum revenue in single-game GaaS markets, thus there are rational pricing strategies for firms $a$ and $b$. This is a unique equilibrium where firms $a$ and $b$ pursue rational strategies and gamers purchase in equilibrium.

One of the main objectives of any firm is the market share. Obviously, the ultimate market shares for firm $a$ and $b$ depends on initially sold units but interestingly they approximate each other regardless of the initial value.

\subsection{Bundle Model}

In our model setup, there are $i$ firms in $j$ games of the market. Gaming markets develop over time, generally with the introduction of a disruptive technology because network externalities require time to affect a market. For example, it took Nintendo years to develop a GaaS enabled ecosystem and benefit from hedonic characteristics of online interactive services (device and GaaS) of the gaming market. Therefore, most game markets start with independent GaaS firms serving each game. The best representation of a precompetition gamer market is the case where firms independently serve separate games to the market. In short, in the basic model, we consider that bundling externalities do not come into effect. On the other hand, information goods inherently exhibit network externalities within a market [21]. Therefore, in the basic model we consider GaaS to exhibit delayed positive network externalities despite the fact that cross-market externalities do not exist.

We consider a two-period pricing game with two firms. Price $p_{t}^{i}$ represents the price of firm $i$ in period $t$. Gamers make purchase decisions based on their utilities. The term $\mathrm{x}^{i}$ is the distance of the gamer buying the service from firm $i$. In addition, the term $\mathrm{c}_{\mathrm{s}}$ represents any costs incurred to switch. The initial picture looks as shown in figure 3:

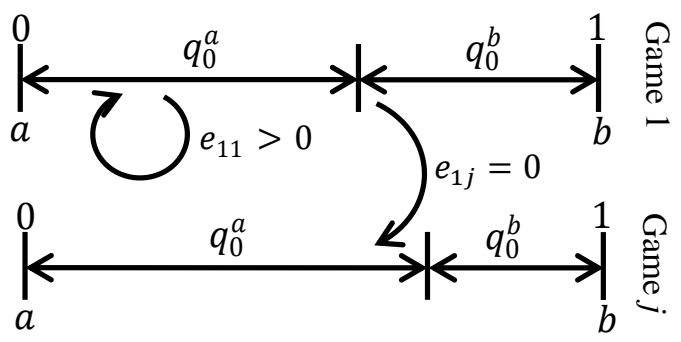

Figure 3. Illustration of the basic model

For simplicity, we denote $e_{11}$ as $e$, and omit the subscript $j$ in $p_{j t}^{i}$ and $q_{j t}^{i}$. The net utility of the indifferent gamer for firm $a$ in the second period can be characterized as:

$$
\begin{aligned}
& u-\alpha x^{a}-p_{2}^{a}+e q_{1}^{a}= \\
& u-\alpha\left(1-x^{a}\right)-p_{2}^{b}-c_{s}^{a}+e q_{1}^{b}
\end{aligned}
$$

The indifferent gamer determines new market shares for firm $a$ and $b$ at the end of the second period.

We use backward induction to find equilibrium prices and quantities sold to represent market shares. First, we start with the second period solution, and then we solve the maximization problem for the first period profits to find equilibrium prices and quantities 
sold. As mentioned in table $1, q_{t}^{i}$ denotes quantity sold by firm $i$ in period $t$.

The net utility of firm $b$ 's indifferent gamer in the second period is:

$$
\begin{aligned}
& u-\alpha\left(1-x^{b}\right)-p_{2}^{b}+e q_{1}^{a}= \\
& u-\alpha x^{b}-p_{2}^{a}-c_{s}^{b}+e q_{1}^{b}
\end{aligned}
$$

We can determine the new allocation of market share for firm $a$ and $b$ at the end of the second period by determining the quantity of switching gamers. To find market shares for the second term, we start by identifying gamers who switch:

Gamers will switch from firm $a$ to firm $b$ when $c_{s}^{a}<\alpha\left(2 \mathrm{x}^{\mathrm{a}}-1\right)+\mathrm{p}_{2}^{\mathrm{a}}-\mathrm{p}_{2}^{\mathrm{b}}+e\left(q_{1}^{b}-q_{1}^{a}\right)$.

Similarly, firm $b$ gamers switch to firm $a$ when $c_{s}^{b}<$ $\alpha\left(1-2 x^{b}\right)-p_{2}^{a}+p_{2}^{b}+e\left(q_{1}^{b}-q_{1}^{a}\right)$. Please note that switching cost can be different for each gamer since it is a distribution. Such switching costs bring additional trade-offs over the heterogeneity of tastes. For example, consider two gamers where one is closer to firm $a$ in tastes. Normally we would expect the closer gamer to stay with firm $a$ and the farther gamer to switch, however, if the closer gamer's switching cost is low, and the farther gamer's switching cost is high, then the farther gamer can stay with the firm because of high switching costs and the closer gamer may switch to the rival's service.

We assume that $\alpha<p_{2}^{a}-p_{2}^{b}$ to avoid the negative probability of switching and an interior location $x$ for the gamer. This assumption not only improves tractability in the general model, but also it is a better representation of reality. Price $p$ in our model includes inherent penalties of switching, therefore a gamer's switching cost will be less than the price difference, or else the gamer would not switch. These conditions are checked for all possible cases (negative and positive) of optimal solutions.

Let $n_{t j}^{k l}$ be the quantity of gamers who bought from $l$ in period $t-1$, and firm $k$ in period $t$, in market game $j$. For example, gamers who switched to firm $b$ from firm $a$ in period 2 are represented as $n_{2 j}^{b a}$. Therefore, gamers staying with firm $a$ can be found through the following calculation:

$$
n_{2 j}^{a a}=\int_{0}^{q_{1}^{a}}\left(\int_{\alpha(2 x-1)+p_{2}^{a}-p_{2}^{b}+e\left(q_{1}^{b}-q_{1}^{a}\right)}^{\theta} \frac{1}{\theta} d s\right) d x
$$

$=\frac{q_{1}^{a}\left(\alpha\left(1-q_{1}^{a}\right)-p_{2}^{a}+p_{2}^{b}+e\left(q_{1}^{a}-q_{1}^{b}\right)+\theta\right)}{\theta}$

Gamers switching from firm $a$ to $b$ :

$$
\begin{gathered}
n_{2 j}^{b a}=q_{1}^{a}-n_{2 j}^{a a} \\
=\frac{q_{1}^{a}\left(\alpha\left(q_{1}^{a}-1\right)+p_{2}^{a}-p_{2}^{b}-e\left(q_{1}^{a}-q_{1}^{b}\right)\right)}{\theta}
\end{gathered}
$$

Gamers staying with firm $b$ :

$$
\begin{aligned}
& n_{2 j}^{b b}=\int_{q_{1}^{a}}^{1}\left(\int_{\alpha(1-2 x)-p_{2}^{a}+p_{2}^{b}+e\left(q_{1}^{b}-q_{1}^{a}\right)}^{\theta} \frac{1}{\theta} d s\right) d x \\
& =\frac{\left(q_{1}^{a}-1\right)\left(q_{1}^{a}(\alpha+e)-q_{1}^{b} e+p_{2}^{a}-p_{2}^{b}+\theta\right)}{\theta}
\end{aligned}
$$

Gamers switching from firm $b$ to firm $a$ :

$$
\begin{gathered}
n_{2}^{a b}=1-q_{1}^{a}-n_{2}^{b b} \\
=\frac{\left(q_{1}^{a}-1\right)\left(q_{1}^{a}(\alpha+e)-q_{1}^{b} e+p_{2}^{a}-p_{2}^{b}\right)}{\theta}
\end{gathered}
$$

Market share for firm $a$ at the end of period 2:

$$
\begin{gathered}
q_{2}^{a}=n_{2}^{a a}+n_{2}^{a b} \\
=q_{1}^{a}+\frac{p_{2}^{b}-p_{2}^{a}+e\left(2 q_{1}^{a}-1\right)\left(q_{1}^{a}-q_{1}^{b}\right)}{\theta}
\end{gathered}
$$

Market share for firm $b$ at the end of period 2:

$$
\begin{gathered}
q_{2}^{b}=n_{2}^{b b}+n_{2}^{b a} \\
=1-q_{1}^{a}+\frac{p_{2}^{a}-p_{2}^{b}-e\left(2 q_{1}^{a}-1\right)\left(q_{1}^{a}-q_{1}^{b}\right)}{\theta}
\end{gathered}
$$

Firm $i$ maximizes its second period profit.

$$
\max _{p} \pi_{2}^{i}=p_{2}^{i} q_{2}^{i}
$$

First order conditions give us equilibrium prices as:

$$
\begin{aligned}
& p_{2}^{a *}=\frac{\left(1+q_{1}^{a}\right) \theta+e\left(2 q_{1}^{a}-1\right)\left(q_{1}^{a}-q_{1}^{b}\right)}{3} \\
& p_{2}^{b *}=\frac{\left(2-q_{1}^{a}\right) \theta-e\left(2 q_{1}^{a}-1\right)\left(q_{1}^{a}-q_{1}^{b}\right)}{3}
\end{aligned}
$$


Equilibrium quantities sold are:

$$
\begin{aligned}
& q_{2}^{a *}=\frac{\left(1+q_{1}^{a}\right)}{3}+\frac{e\left(2 q_{1}^{a}-1\right)\left(q_{1}^{a}-q_{1}^{b}\right)}{3 \theta} \\
& q_{2}^{b *}=\frac{\left(2-q_{1}^{a}\right)}{3}+\frac{e\left(2 q_{1}^{a}-1\right)\left(q_{1}^{a}-q_{1}^{b}\right)}{3 \theta}
\end{aligned}
$$

As a result of the second period profit maximization, we obtain profits as a function of quantities sold in the first period:

$$
\begin{aligned}
& \pi_{2}^{\mathrm{a} *}=\frac{\left(e\left(2 q_{1}^{a}-1\right)\left(q_{1}^{a}-q_{1}^{b}\right)+\left(1+\mathrm{q}_{1}^{\mathrm{a}}\right) \theta\right)^{2}}{9 \theta} \\
& \pi_{2}^{\mathrm{b} *}=\frac{\left(e\left(2 q_{1}^{a}-1\right)\left(q_{1}^{a}-q_{1}^{b}\right)-\left(2-\mathrm{q}_{1}^{\mathrm{a}}\right) \theta\right)^{2}}{9 \theta}
\end{aligned}
$$

For the first period maximization problem, we follow a process similar to the second period. First, we identify the indifferent gamers to find switching costs $c_{s}$ in terms of $x^{i}$ and prices.

The net utility of the indifferent gamer for firm $a$ in the first period is:

$$
\begin{aligned}
& u-\alpha x^{a}-p_{1}^{a}+e q_{1}^{a}= \\
& u-\alpha\left(1-x^{a}\right)-p_{1}^{b}-c_{s}+e q_{1}^{b}
\end{aligned}
$$

The net utility of firm $b$ 's indifferent gamer is:

$$
\begin{aligned}
& u-\alpha\left(1-x^{b}\right)-p_{1}^{b}+e q_{1}^{a}= \\
& u-\alpha x^{b}-p_{1}^{a}-c_{s}+e q_{1}^{b}
\end{aligned}
$$

Subsequently, we solve the maximization problem for the first period profits to find equilibrium prices and quantities sold. Tracing previous steps shows that there are optimal pricing strategies for firm $a$ and $b$ in the basic model.

Theorem 2: There exists a solution for the maximum revenue in bundled Gaas markets, thus there are rational pricing strategies for firms $a$ and $b$.

\subsection{Pricing with GaaS Externalities}

Under the assumption that positive network externalities are present across GaaS, we introduce a more sophisticated parameter $e$. In this case, $e_{h j}$ represents the delayed positive network externalities of the quantity sold in market game $h$ on market game $j$. This externality means that the utility of the gamer benefits from a compatible game sold in a connected market. For example, when a firm such as Nintendo sells an online game service, it has the potential to affect sales of complementary digital goods and services. Complementary service offerings and social characteristics of collaborative games increase the utility for the gamer. This benefit creates value both for the user playing a single game and for the gamer using bundled services.

The main challenge for such a platform is to get the pricing right. In our second case, we develop a pricing strategy when cross-market externalities are enabled though technologies such as GaaS. Here is an illustration of how cross-market externalities affect our model.

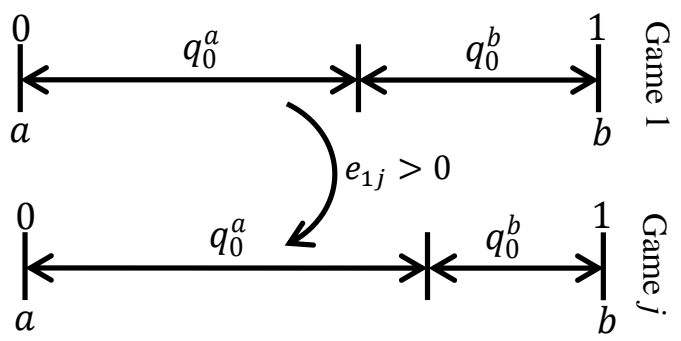

Figure 2. Illustration of the initial condition for the extended model: cross-market externality

We update gamer utilities and the indifferent gamer equation for firm $a$ in period 2 becomes:

$$
\begin{aligned}
& u-\alpha x^{a}-p_{2}^{a}+e_{h j} q_{1}^{a}=u-\alpha\left(1-x^{a}\right)-p_{2}^{b}- \\
& c_{s}+e_{h j} q_{1}^{b} .
\end{aligned}
$$

Similarly, the indifferent gamer for firm $b$ in period 2 can be characterized as:

$$
\begin{aligned}
& u-\alpha\left(1-x^{b}\right)-p_{2}^{b}+e_{h j} q_{1}^{b}= \\
& u-\alpha x^{b}-p_{2}^{a}-c_{s}+e_{h j} q_{1}^{a}
\end{aligned}
$$

Next, we solve the base model with the externality extension.

With cross-market externalities, gamers will switch from firm $a$ to firm $b$ when $c_{s}^{a}<\alpha\left(2 x^{a}-\right.$ 1) $+p_{2}^{a}-p_{2}^{b}+e_{h j}\left(q_{1}^{b}-q_{1}^{a}\right)$. Similarly, firm $\mathrm{b}$ gamers switch to firm a when $c_{s}^{b}<\alpha\left(1-2 x^{b}\right)-$ $p_{2}^{a}+p_{2}^{b}+e_{h j}\left(q_{1}^{a}-q_{1}^{b}\right)$.

We solve the profit maximization problem for prices and units sold similar to the previous section. Tracing the steps in section 3.1 with $e_{h j} \in(0,1)$, we find that: 


$$
\begin{aligned}
& \left(q_{2}^{a *}\right)_{\begin{array}{c}
\text { cross-market } \\
\text { externalities }
\end{array}}>\left(q_{2}^{a *}\right)_{\text {basic model }}>0 \\
& \left(p_{2}^{a *}\right)_{\text {cross-market }}^{\text {externalities }}
\end{aligned}
$$

Proposition 1: Cross-market externalities increase the benefits to the market leader in terms of quantities sold.

Proposition 2: The market leader can charge a higher price in the presence of positive cross-market externalities without losing market share.

Please note that these results only hold for the market share leader firm, because the externality effects across the periods conflict with the intermarket externality effects for the follower firm.

\section{How to test findings empirically?}

Analytical models are very useful to define sterilized relationships between constructs. On the other hand, studies that utilize pure analytical modeling methodology may raise a healthy skepticism among the audience. This section is included to provide guidance, and outline, how the key parts of the analytical model presented in this paper could be tested empirically, and validated.

First, it is essential to transform propositions in this study into testable (i.e. rejectable) assumptions or implications (hypotheses.) For example, proposition 1 (Cross-market externalities increase the benefits to the market leader in terms of quantities sold) is a great candidate to become a measurable and testable hypothesis. The dependent variable "quantities sold" is already measured in most firms, and externalities could be measured through surveys or customer panels to understand customers' utility and the role of network externality. Then, linear regression (or a more complex statistical method) could be used to validate the model.

Second, the contribution and inferences drawn from the model and the empirical validation must be aligned. Particularly, inferences drawn from a potential empirical validation should be related to the inferences drawn from the model.

Third, it may be useful to keep in mind that empirical findings might not validate the analytical model. This is a finding in itself. Researchers must be critical in their thinking. As aforementioned, analytical models help us investigate sterilized relationships between constructs, but reality is never sterile. If empirical tests show a different trend, it may be useful to investigate why and under which cases analytical findings hold, and when do they deviate.

\section{Conclusions}

Overall, in this study, we are investigating how GaaS firms can make pricing decisions to benefit from bundling and externalities to maximize game revenues and increase gamer utility. This question is, of course, multi-faceted. Drawing on the capabilities of analytical modeling, we have identified several related results, which currently interest theory and practice. They concern monetization strategies in GaaS market, and economic principles of game design. Our findings could also support business model design and strategic decision-making in practice.

Advances in information technologies provided us with smart services that exhibit complex interactions. Cross-game externalities such as the ones in the Games as a Service (GaaS) enabled markets are an example of these complex properties. For example, making modular and connected GaaS offerings benefit from externalities. In our study, we developed a model incorporating both within-market and cross-game externality effects in an industry that has multiple games. To our knowledge, this is the first model about GaaS markets. Therefore, this study also contributes to the e-Commerce literature as the first analytical GaaS pricing model.

On the other hand, practitioners in the GaaS enabled market are challenged in developing viable pricing models in such complex business scenarios. Practitioners currently use pricing models developed for conventional service models. This study offers a new approach, supported by a novel model, for pricing smart services enabled by GaaS.

Our findings suggest that, even with the presence of positive and delayed network externalities in a gaming market, there is a solution for the optimal revenue. Moreover, we find that cross-market externalities provide opportunities for those firms who are willing to operationalize their pricing and market share strategies around them. Specifically, firms that are willing to identify cross-market externalities can benefit in terms of higher market share and prices. Perhaps firms such as Apple or Google have already benefited from externalities by instinctually creating ecosystems connected to games. If there is such a 
phenomenon, we explain the rationale behind it with an analytical model.

The main limitations of this research are due to the analytical modeling methodology we employed. First, arguments and propositions in this study have not been tested empirically and they are bound by the model assumptions. For example, we anticipated network externalities would be positive, which is aligned with the e-Commerce and economics literature [22, 23, 24]. However, in real life, we observe a diminishing rate of return for the externality effect, and even sometimes, it is negative. Indeed, an example of negative network externalities has been the departure of young social media users of Facebook games when parents became users and sent game play requests to their children.

Finally, but maybe most importantly, data collected from such smart devices would lead to micro-segmentation and advanced marketing methods that would target individual gamers rather than wide segments. Analyzing the data collected from gaming devices, firms can direct promotions to extract a higher utility from gamers. To summarize, our model can be improved by considering synergies other than positive network externalities among the sides of a GaaSenabled smart services market.

Each one of the limitations in this study provides an opportunity for a future research direction. First, in this study, we use a relatively simplified model of the network externality concept. Our model could be improved by considering a more sophisticated form (probably concave) externality function. Second, the model is based on two periods. Extending the time horizon to include multiple periods can provide additional insights into the impact of network externalities on gamers' utility functions. Finally, as outlined in the previous section, validation of our findings creates an opportunity for an empirical study for the pricing of GaaS enabled markets. 


\section{References}

[1] T. Derdenger, "Technological Tying and the Intensity of Price Competition: An Empirical Analysis of the Video Game Industry," Quantitative Marketing and Economics, 12(2), 2014, pp. 127-165.

[2] T. Keskin, and N. Taskin, "Strategic Pricing of Horizontally Differentiated Services with Switching Costs: A Pricing Model for Cloud Computing," International Journal of Electronic Commerce 19(3), 2015, pp. 34-53.

[3] D.G. Gopal, and S. Kaushik, "Emerging Technologies and Applications for Cloud-Based Gaming: Review on Cloud Gaming," Emerging Technologies and Applications for Cloud-Based Gaming, 2016, p. 67.

[4] Technology Business Research, "2016 SaaS Industry Market Report: Key Global Trends \& Growth Forecasts," Retrieved on April 30, 2017, from

https://financesonline.com/2016-saas-industry-marketreport-key-global-trends-growth-forecasts/

[5] M. Armbrust, A. Fox, R. Griffith, A.D. Joseph, R. Katz, A. Konwinski, G. Lee, G., D. Patterson, A. Rabkin, I. Stoica, M. and Zaharia, M. "A View of Cloud Computing," Communications of the ACM, 2010, 53(4), pp. 50-58.

[6] R. Buyya, C.S. Yeo, S. Venugopal, J. Broberg, and I. Brandic, "Cloud Computing and Emerging It Platforms: Vision, Hype, and Reality for Delivering Computing as the 5th Utility," Future Generation computer systems, 2009, 25(6), pp. 599-616.

[7] P. Mell, and T. Grance, "The NIST Definition of Cloud Computing," Laboratory, National Institute of Standards and Technology, 2011.

[8] L. Qian, Z. Luo, Y. Du, and L. Guo, "Cloud Computing: An Overview," in Cloud Computing. Springer, 2009, pp. 626-631.

[9] M. Vouk, M. 2008. "Cloud Computing-Issues, Research and Implementations," Journal of Computing and Information Technology, 2008, 16(4), pp. 235-246.

[10] C. Weinhardt, D. Anandasivam, B. Blau, D. Borissov, D. Meinl, D. Michalk, and J. Stößer, "Cloud Computing - a Classification, Business Models, and Research Directions," Business \& Information Systems Engineering, 2009, 1(5), pp. 391-399.

[11] W.J. Orlikowski, and C.S. Iacono. "Research commentary: Desperately seeking the "IT" in IT research A call to theorizing the IT artifact," Information Systems Research, 2001 12(2), pp 121-134.

[12] Q. Zhang, L. Cheng, and R. Boutaba, "Cloud Computing: State-of-the-Art and Research Challenges," Journal of Internet Services and Applications, 2010, 1(1), pp. 7-18.
[13] T. Behrend, E. Wiebe, J. London, and E. Johnson, "Cloud Computing Adoption and Usage in Community Colleges," Behaviour \& Information Technology, 2011, 30(2), pp. 231-240.

[14] L.M. Kaufman, "Data Security in the World of Cloud Computing," Security \& Privacy, 2009, 7(4), pp. 61-64.

[15] W. Kim, "Cloud Computing Adoption," International Journal of Web and Grid Services 2011, 7(3), pp. 225-245.

[16] S. Dawson, and M. Kim, "External and Internal Trigger Cues of Impulse Buying Online," Direct Marketing, 2009, 3(1), pp. 20-34.

[17] S. Sheng, A. Parker, and K. Nakamoto, "The Effects of Price Discount and Product Complementarity on Consumer Evaluations of Bundle Components," Journal of Marketing Theory and Practice, 2007, 15(1), pp. 53-64.

[18] X. Yin, and H. Jin-Song, "Effects of Price Discounts and Bonus Packs on Online Impulse Buying," Social Behavior \& Personality, 2014, 42(8), pp. 1293-1302.

[19] A. Mishra, and H. Mishra, "The Influence of Price Discount versus Bonus Pack on the Preference for Virtue and Vice Foods," Journal of Marketing Research, 2011, 48(1), pp. 196-206.

[20] H.L. Lee, and M.J. Rosenblatt, "A Generalized Quantity Discount Pricing Model to Increase Supplier's Profits," Management Science, 1986, 32(9), pp. 1177-1185.

[21] E. Brynjolfsson and C. F. Kemerer, "Network externalities in microcomputer software: An econometric analysis of the spreadsheet market," Management Science, vol. 42, pp. 1627-1647, Dec 1996.

[22] N. L. Katz, and C. Shapiro, "Network Externalities, Competition, and Compatibility", American Economic Review, 75(3), 1985, pp. 424-440.

[23] Y. Bakos, and E. Katsamakas, "Design and Ownership of Two-Sided Networks: Implications for Internet Platforms", Journal of Management Information Systems, 25(2), 2008, pp. 171-202.

[24] R. Seamans, and F. Zhu, "Responses to entry in multisided markets: The impact of Craigslist on local newspapers", Management Science, 60(2), 2014, pp. 476493 